\title{
The perfective and imperfective aspects in Xhosa*
}

\author{
Stefan Savić \\ Department of English Language and Linguistics, Rhodes University, South Africa \\ E-mail: stefansavicz@gmail.com
}

\begin{abstract}
The present corpus study aims to investigate the semantics of the perfective and the imperfective aspects in Xhosa. In a large number of studies that investigate tense and aspect in the Nguni languages, the observations are mostly based on invented, context-free sentences, which do not necessarily reflect the complex semantics of these two categories. The data in the present study come from corpora, thus making it possible to test the study's hypothesis with examples from natural language use. At the same time, the instances that cannot be accounted for by this hypothesis provide evidence that can be used for its improvement. The present study tests the hypothesis that the perfective aspect denotes an eventuality that is conceived of as bounded or as an indivisible whole, and that the imperfective aspect represents an eventuality as durative or iterated. The data collected in this study consist of recent past perfective and imperfective verbs that are tested for their ability to hold true at more than one point in time. The underlying assumption is that, unlike durative and iterated ones, bounded events cannot hold true at more than one point in time. The results show that the perfective/imperfective opposition in Xhosa correlates to a large extent with the view of an eventuality as bounded. However, a significant number of the verbs analysed cannot be accounted for by this explanation. The choice of aspect in these cases points toward other factors, such as factuality, number of occurrences, information structure, and sequencing of eventualities.
\end{abstract}

Keywords: grammatical aspect, boundaries, Xhosa

\section{Introduction}

Xhosa is a Nguni language of the Bantu family spoken primarily in South Africa. It is an agglutinating language that exhibits a rich verbal paradigm. In the current study, it is claimed that in addition to its two aspects, the perfective and the imperfective, Xhosa distinguishes between five tenses: two past tenses, two future tenses, and the present tense.

\footnotetext{
* I would like to thank the Sandisa Imbewu Fund for the financial support. I would also like to thank Zukisani Dyasi, Hlumela Mkabile, Sibusiso Klaas, Nomava Mercy Tunzelana, and Olwethu Zeleni for translating the examples from Xhosa, as well as Dr Eva-Marie Bloom Ström, Dr Mark de Vos, and Dr Silvester Ron Simango for their advice and academic support.
} 
Despite a number of studies dealing with the verbal paradigm of the $\operatorname{Nguni}^{1}$ languages, disagreement regarding the semantics of certain verb forms in these languages still prevails in the literature. For example, Groenewald (2014) claims that Xhosa expresses the category of aspect in compound verbs with the auxiliary verb - $b a$ 'be', whereas Posthumus (2008) considers these forms to represent relative tenses. In order to resolve this issue, insights from recent research on aspect need to be applied in the analysis of the verbal paradigm in Xhosa. In this respect, Bary (2009) and Crane (2012) define grammatical aspect with the notion of "boundedness", which is essential for the understanding of the conceptualisation of eventualities, as well as for the understanding of the interaction between grammatical aspect and lexical aspect.

The aim of this study is to verify whether perfective verbs indicate eventualities that are viewed as bounded, indivisible wholes and whether imperfective verbs represent eventualities as durative or iterative. It is hypothesised that perfective verbs refer to eventualities that can hold true at only one point in time; unlike those represented by imperfective verbs, which hold true at more than one point in time. This approach makes it possible to clarify the other factors in addition to lexical properties of the verb phrase that influence the choice of grammatical aspect.

In studies that deal with the verbal paradigm of the Nguni languages, it is common practice to use invented, context-free sentences. Sentence elicitation is an adequate method for gaining an idea of the basic semantics of a language's temporal and aspectual markers. However, it is natural language use that provides a context for the analysed sentences, thereby facilitating the testing of hypotheses. For these reasons, the data used in the present study come from three Resource Management Agency (RMA) corpora of Xhosa: the Genre Classification Corpus (Snyman et al. 2012), the African Speech Technology (AST) Text Corpus (Roux et al. 2001), and the National Centre for Human Language Technology (NCHLT) Text Corpus (Eiselen and Puttkammer 2014). In addition to providing empirical evidence for its claims regarding aspectual semantics in Xhosa, the study indicates the areas that should receive more attention in future research on aspect.

\section{Tense, lexical aspect, and grammatical aspect}

In this section, tense, lexical aspect, and grammatical aspect will be discussed. To facilitate understanding of the differences between these categories, Reichenbach's (1947) notions of 'speech time', 'event time', and 'reference time' need to be introduced. Whereas 'speech time' (henceforth referred to as "S") represents the time at which an utterance is made, 'event time' (henceforth referred to as "E") is the time at which the reported eventuality takes place. Reichenbach (1947) uses the notion of "reference time"3 (henceforth referred to as "R") to account for the semantics of different tenses in English:

\footnotetext{
${ }^{1}$ Instead of referring to literature that deals solely with Xhosa, the verbal paradigm discussed here includes references to the grammars of the other Nguni languages, namely Zulu and Swati. The verbal paradigms of Zulu and Swati are almost identical to that of Xhosa. Referring to grammars of the Nguni languages seems to be a common practice in other studies (cf. e.g. Nxopo (1993), Gowlett (2003), and Posthumus (2008)).

2 Two different theories have been especially prominent in research on the perfective/imperfective opposition, namely the theories of boundedness and totality (Dahl 1985; Dickey 2000). The differences between these theories will be briefly addressed in section 2.3.1. However, at this point the 'boundedness' approach to grammatical aspect will be used to refer to both views, for the sake of simplicity.

${ }^{3}$ Reichenbach (1947) does not provide an explicit definition of reference time (Borik 2002).
} 
(1) She arrived with them.

$\left(\mathrm{E}, \mathrm{R} \_\mathrm{S}^{4}\right)$

(2) She has arrived with them.

$\left(\mathrm{E} \_\mathrm{R}, \mathrm{S}\right)$

(3) She had arrived when we came home.

(E_R_S)

In (1), the past eventuality indicates that $\mathrm{R}$ co-occurs with $\mathrm{E}$ and both points precede $\mathrm{S}$. In (2), the past eventuality is seen from the present moment; i.e. $\mathrm{S}$ and $\mathrm{R}$ coincide, while $\mathrm{E}$ precedes them. In (3), the past eventuality is seen from another past point; i.e. E precedes R, which in turn precedes $\mathrm{S}$.

\subsection{Absolute and relative tenses}

Comrie's (1976) view of tense is that it locates situations in time, usually with reference to the present moment, though also with reference to other situations. This definition includes both absolute and relative tenses. Johnson (1981), Klein (1994), and Bohnemeyer (2014) ${ }^{5}$ define "absolute tense" as the location of $\mathrm{R}$ relative to $\mathrm{S}^{6}$. In other words, absolute tense is a category that assigns an eventuality to the past, the present, or the future, depending on the position of S. For example, in (4), the past tense verb "arrived" is an absolute tense, which indicates that the eventuality of arriving takes place before $S$.

Relative tense assigns an eventuality to a point in time that is not $S$ (Nurse 2008). In (5), the past perfect verb "had arrived" represents a relative tense, because the time of arrival is determined relative to another point in the past.

(4) She arrived with them.

(5) She had already arrived.

The importance of distinguishing absolute tense from grammatical aspect lies in the fact that many studies of the Nguni verbal paradigm do not make a clear distinction between these two categories. This issue will be addressed in section 2.3. Relative tenses are especially relevant for section 3.1, where the semantics of Nguni compound verbs with the auxiliary verb - $b a$ ' $b e$ ' will be discussed.

\subsection{Lexical aspect}

"Lexical aspect", "Aktionsart", or "situation type"7 refers to the various classes to which verb phrases belong based on their "inherent internal temporal structure" (Crane 2012:209). Perhaps the most well known is Vendler's (1967) classification of verb phrases into four situation types: states, activities, accomplishments, and achievements ${ }^{8}$. Based on telicity and the presence of successive phases of the structure, verb phrases can fall into one of these

\footnotetext{
${ }^{4}$ In the schematic representation of the three tenses, commas indicate the simultaneity of two points in time, whereas the underscore indicates temporal distance between two points.

5 The terminology Klein (1994) and Bohnemeyer (2014) employ diverges from that introduced by Reichenbach (1947). "E" corresponds to Klein's (1994) "situation time", "S" to "utterance time", and "R" to "topic time".

${ }^{6}$ Note that opposing views exist, such as that expressed in Borik (2002), according to which absolute tense represents the location of $\mathrm{E}$ on the timeline relative to $\mathrm{S}$.

${ }^{7}$ Lexical aspect, Aktionsart, or situation type is a distinct category from that of grammatical aspect. Throughout the present study, lexical aspect will be referred to using the adjective "lexical", in order to distinguish it from grammatical aspect.

${ }^{8}$ Comrie (1976) added a fifth class termed "semelfactive" for eventualities that occur only once.
} 
four situation types (Rothstein 2004). Telicity divides verb phrases into telic and atelic. Telic verb phrases are those that represent a change of state or those that are bound to come to an end, such as "fall" or "read a book". Atelic verb phrases do not indicate any change of state, such as "read" or "run". The second feature that divides verb phrases into two groups is their structure, which may consist of successive phases ("swim", "draw", "walk a mile", "build a house") or not (such as "love", "know", "fall", and "sneeze"). States and activities are atelic, whereas achievements and accomplishments are telic. States ("love", "know") and achievements ("fall", "break") do not consist of successive phases, as opposed to activities ("read", "run", "swim", "draw") and accomplishments ("build a house", "walk a mile").

However, Beuchat (1966) and Botne and Kershner (2000) do not apply Vendler's (1967) classification in their analyses of verbs in Zulu. Instead, they follow the distinction between inchoative (or "change-of-state") and non-inchoative (or "durative") verbs, because Zulu has a large number of the former (Botne and Kershner 2000). Inchoative verbs, such as -bamba 'grab', 'seize'9 are punctual (instantaneous), and they express a "change or transition from one state to another" (Botne and Kershner 2000:165), whereas the non-inchoative, such as -phatha 'hold', do not ${ }^{10}$. Crane (2012) follows the same distinction in her study of tense and aspect in Totela, another Bantu language.

In their analysis of Zulu verbs, Botne and Kershner (2000) adopt Freed's (1980) and Botne's (1983) framework of verb structure, according to which an eventuality consists of three phases: onset $(\mathrm{O})$, nucleus $(\mathrm{N})$, and coda $(\mathrm{C})$. Whereas $\mathrm{N}$ constitutes the characteristic part of a situation, $\mathrm{O}$ represents its preparatory and $\mathrm{C}$ its terminal phase. $\mathrm{C}$ and $\mathrm{O}$ "may or may not be lexically entailed" (Crane 2012:210). It is primarily in the nuclear phase that inchoative verbs differ from non-inchoative verbs. Botne and Kershner (2000) schematise the structure of inchoative verbs such as -bamba 'grab', 'seize' and that of non-inchoative verbs, such as -phatha 'hold' as in Figure 1.

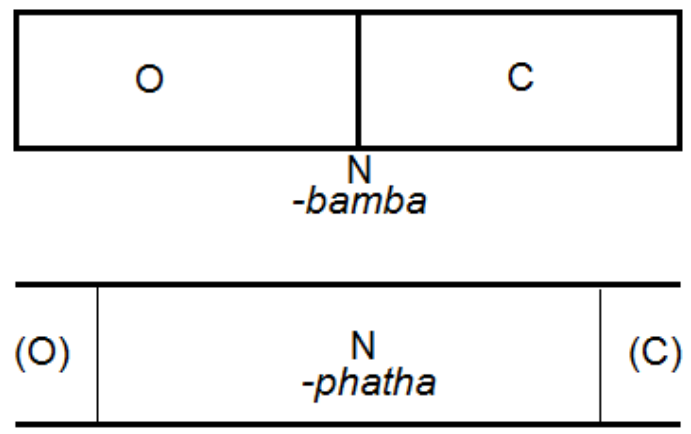

Figure 1: The structure of inchoative verbs (upper) with a punctual nucleus and non-inchoative verbs (lower) with a durative nucleus, according to Botne and Kershner (2000)

\footnotetext{
${ }^{9}$ The translation of the Zulu verb -bamba as 'grab' or 'seize' is provided by Botne and Kerhsner (2000). In section 4 of the present study, -bamba is translated as 'catch' or 'hold'.

${ }^{10}$ Note that the distinction between inchoative and non-inchoative verbs differs from telicity. Whereas "telicity" refers to the existence of an inherent endpoint of an event, the distinction between inchoative and non-inchoative verbs is based on whether the verb phrases can denote a punctual eventuality or not. When compared to Vendler's (1967) situation types, inchoative verbs would correspond to achievements, whereas the non-inchoative ones would include activities and accomplishments (Botne and Kershner 2000).
} 
The two different types of verb nuclei are important for understanding the semantics of grammatical aspect, which is discussed in the following section.

\subsection{Grammatical aspect}

Comrie (1976:3) defines "grammatical aspect" as "the internal temporal constituency of a situation". Klein (1994), Gvozdanović (2011), and Bohnemeyer (2014) ${ }^{11}$ see it as a relation between $\mathrm{E}$ and $\mathrm{R}^{12}$. Unlike absolute tenses, which temporally locate an eventuality relative to $\mathrm{S}$, grammatical aspect represents the way in which the speaker chooses to view the structure of an eventuality.

Grammatical aspect should also not be confused with lexical aspect, which refers to the inherent structural properties of a particular verb phrase. For example, the English verb phrase "run a mile" has an inherent end. Grammatical aspect enables the speaker to use grammatical means to change the structural properties of a verb phrase, irrespective of its lexical aspect. For example, "she ran a mile" and "she was running a mile" have the same lexical aspect, but their grammatical aspect differs (the former is non-progressive and the latter is progressive). The two clauses exhibit different structural properties, in that the former represents the eventuality as complete and the latter depicts it as ongoing.

As with temporal categories, the overt expression of aspectual categories depends on the language. Some languages, such as the Slavic languages, distinguish between the perfective aspect and the imperfective aspect. Languages with the perfective/imperfective dichotomy have the grammatical means to represent an eventuality as an indivisible whole by using the perfective aspect (Comrie 1976; Dickie 2000). In such languages, situations that are perceived as durative or iterated will be expressed with the imperfective aspect. The imperfective aspect in one language can correspond to smaller aspectual categories in another language (Comrie 1976). For example, the imperfective aspect covers the habitual aspect, which refers to habitual situations, and the progressive aspect, which describes ongoing eventualities when seen from one point in time (Comrie 1976; Dahl 1985).

\subsubsection{Perfective/imperfective opposition}

For decades, two traditions have occupied a significant place in the debate regarding the semantics of the perfective/imperfective opposition. These are boundedness theory and totality theory (Dahl 1985; Dickey 2000). According to Comrie (1976), whose views belong to the latter tradition, the perfective aspect represents an eventuality as an indivisible whole without making reference to its internal structure. In the same tradition, the imperfective aspect indicates that an eventuality is viewed in terms of its internal structure. In boundedness theory, whose early proponents include Jakobson (1957), Lindstedt (1985), and Chung and Timberlake (1985), the perfective aspect indicates that the eventuality is viewed together with its internal

\footnotetext{
${ }^{11}$ Bohnemeyer (2014) splits the term " $\mathrm{R}$ " into two different concepts: 'topic time' and 'perspective time'. Topic time is the time within which an eventuality is said to hold true. According to him, grammatical aspect represents the relation between topic time and situation time (E). Perspective time is the time interval that is "anaphorically tracked across clause boundaries" (Bohnemeyer 2014:924). However, in this study, the distinction between "topic time" and "perspective time" will not be made, and they will be regarded as two manifestations of one and the same phenomenon.

${ }^{12}$ Note that significantly divergent views exist as well, such as that expressed by Borik (2002), according to whom grammatical aspect reflects the relation between $\mathrm{R}$ and $\mathrm{S}$.
} 
limit or the endpoint after which it stops. In most studies within these two theoretical traditions, the imperfective is viewed as the unmarked member of the opposition.

Irrespective of theoretical tradition, both views are similar enough to be tested with reference to Mourelatos' (1981) and Bach's (1986) distinction between homogenous and quantised verb phrases, which is based on the verb phrase's structural properties (Bary 2009). Mourelatos (1981) and Bach (1986) make a distinction between these two types of verb phrases that is analogous to the distinction between homogenous and quantised noun phrases (Bary 2009). Homogenous noun phrases can refer to an entity and to a part of that entity at the same time. For example, a part of "milk" is still referred to as "milk". On the contrary, quantised noun phrases are those that denote an entity but do not refer to the proper parts of that entity; e.g. a part of a "house" is not a "house". When applied to verb phrases, the homogenous ones denote an eventuality as much as they denote any part of that eventuality. For example, the verb phrase "to laugh" in (6) is homogenous, because it holds true for the entire eventuality as much as it does for its integral parts.

(6) She laughed.

However, "to write a letter" in (7) is quantised, because it refers to the entire eventuality, but it cannot refer to its integral parts.

She wrote a letter.

In (6) and (7), the homogenous/quantised distinction is illustrated at the level of lexical aspect. Quantised verb phrases rely on the existence of a boundary, i.e. punctual changes of state. States and activities are atelic and homogenous, whereas achievements and accomplishments are telic and quantised (Bary 2009). In the classification of lexical aspect used in Botne and Kershner (2000) and Crane (2012), inchoative verbs entail the existence of a boundary. Therefore, they can be considered quantised. Accordingly, (atelic) non-inchoative verb phrases should be considered homogenous.

Mourelatos (1981), Bach (1986), and de Swart (1998) apply the distinction between homogenous and quantised verb phrases at the level of grammatical aspect as well ${ }^{13}$ (Bary 2009). Irrespective of the verb phrase's lexical aspect, the perfective aspect will render it quantised, whereas the imperfective aspect will render it homogenous (Bary 2009). Bary (2009) provides example sentences from Ancient Greek and French, in which telic verb phrases receive a habitual or a progressive reading in the imperfective. (8) and (9) demonstrate Ancient Greek telic (i.e. bounded) verb phrases in the imperfective. Whereas epi tēn Hellada elaune 'he was marching to Greece' in (8) obtains the progressive interpretation, dōra hoi (...) edidou 'he gave him presents' in (9) obtains a habitual reading:

Entha kai to hiron harma katalipōn tou Dios hote epi tēn Hellada ēlaune, apiōn ouk apelabe ...

'After he (Xerxes) had left the sacred chariot of Zeus there when he was marching to Hellas, on his way back he did not get it back (...)'

Herodotus, Histories, 8.115, cited in Bary (2009)

\footnotetext{
13 A similar observation is made by Dahl (1985), who draws an analogy between the perfective/imperfective opposition and the nominal count/mass distinction.
} 
dōra hoi ana pan etos edidou, kai tēn Babylōna hoi edōke.

'Every year he gave him presents and (once) he gave him Babylon.'

Herodotus, Histories, 3.160, cited in Bary (2009)

Accordingly, atelic (unbounded) verb phrases obtain a new interpretation in the perfective. Thus, the Ancient Greek atelic verb edakruse 'he wept' in the perfective enables an ingressive interpretation, i.e. it indicates the beginning of the eventuality of weeping (Bary 2009):

(10) enthauta ho Xerxēs heōuton emakarise, meta de touto edakruse. Mathōn de min Artabanos ... dakrusanta eireto tade: (...)

'Then Xerxes declared himself happy, and presently he started to weep. Perceiving that he had begun to weep, Artabanos questioned him, saying (...).'

Herodotus, Histories, 7.45-46, cited in Bary (2009)

Another possible reading of atelic verbs in the perfective is what Bary (2009) terms the "complexive interpretation". This means that the entire eventuality, from its beginning to its end, is seen as an indivisible whole or one point in time. In example (11), the atelic participle basileusanta '(he) had reigned' receives a complexive reading:

(11) Aiguptioi meta ton hirea tou Hephaistou basileusanta ... estēsanto duōdeka basileas

'After the priest of Hephaestus had reigned, the Egyptians set up twelve kings.'

Herodotus, Histories, 2.147, cited in Bary (2009)

Examples (8-11) show that the perfective/imperfective opposition adds or removes the boundaries determined by the lexical aspect of the verb phrase. The addition of a new boundary or the removal of an existing one by grammatical aspect can be schematically represented using Botne and Kershner's (2000) verb structure model. Figure 2 shows the imperfective aspect and Figure 3 the perfective aspect ${ }^{14}$.
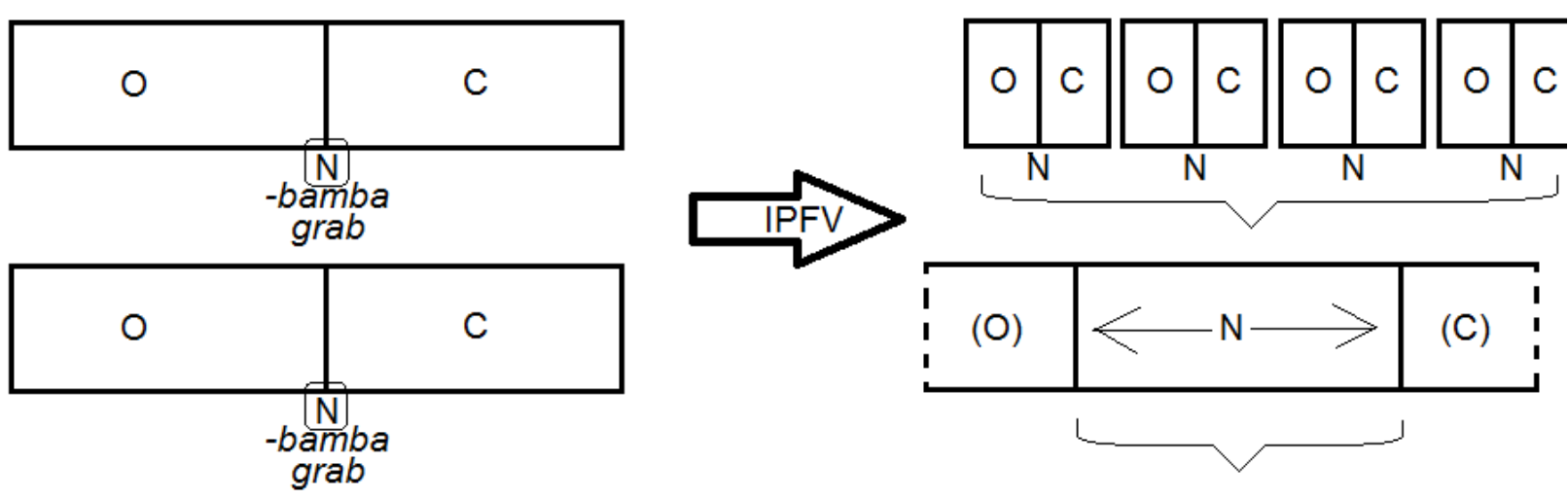

Figure 2: The imperfective aspect removing the boundary from the inchoative verb phrase -bamba 'grab' in Zulu. The top example represents the habitual and the bottom the progressive interpretation.

\footnotetext{
${ }^{14}$ Unbounded verb phrases in the imperfective and bounded verb phrases in the perfective represent cases where grammatical aspect corresponds to the structure of the lexical aspect. Such cases are not shown in Figures 2 and 3.
} 

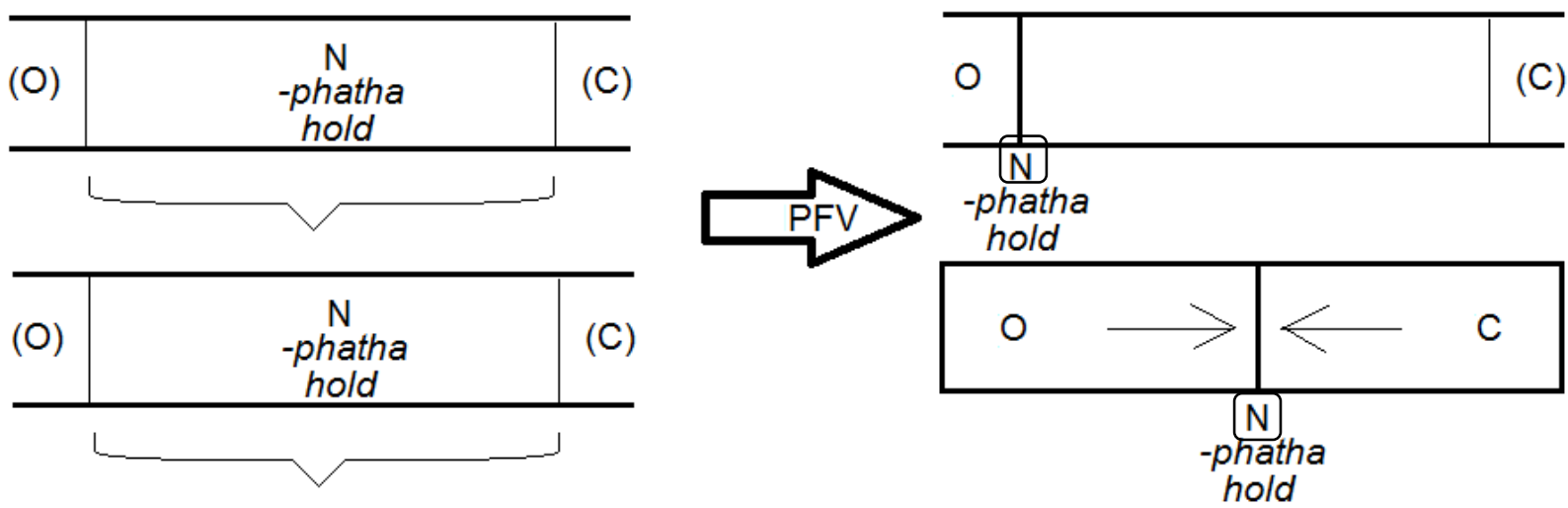

Figure 3: The perfective aspect adding a boundary to the non-inchoative verb phrase -phatha 'hold' in Zulu. The top example represents the ingressive and the bottom the complexive interpretation.

In Figures 2 and 3, it is visible that the boundaries indicated by the lexical aspect and the grammatical aspect are in fact single, punctual (instantaneous) nuclei. In the figures, these nuclei are represented by vertical lines. As shown in Figure 2, the imperfective aspect may multiply the number of punctual nuclei (in the habitual context). Alternatively, the boundary indicated by the punctual nucleus is magnified to the extent that the nucleus appears as a durative one (in the progressive context). The resulting imperfective eventualities are homogenous, as they are semantically equivalent to their integral parts.

Figure 3 shows that the perfective aspect combined with an eventuality with a durative nucleus creates a boundary at the level of the sentence (as opposed to the boundary encoded in the lexical aspect of the verb phrase). The boundary is created by using the starting point (in the ingressive context) or by merging the starting point and the endpoint (in the complexive context). A perfective eventuality is thus quantised at the level of the sentence, which means that the verb phrase that refers to the entire eventuality cannot refer to its smaller, integral parts.

\section{Verbal paradigm of Xhosa}

Xhosa distinguishes between four moods: the indicative, imperative, subjunctive, and participial (Davey 1973; Bryant 2007). As pointed out in the introduction, five tenses are marked in the indicative mood: the present tense, recent past, remote past, immediate future, and remote future. All the past and future forms can be marked with the imperfective aspect by adding the auxiliary verbs $-b a$ 'be' or $-y a$ ' $g o$ '. In the recent past and in the future tenses, only the verb $-b a$ is used.

Compound verbs have a long and a short form. The long form consists of two verb forms, the first with the auxiliary and the second with the main verb. Within both verb forms, the first element is the subject concord (e.g. $n d i$ - for the first person singular, $u$ - for the second person singular), and the second element is the auxiliary verb (-ba or $-y a$ in the first verb form $)^{15}$ or the main verb (in the second verb form). In the short form of compound verbs, the auxiliary verb merges with the subject concord from the second verb form, whereas the subject concord

\footnotetext{
${ }^{15}$ In the past compound verb forms, the auxiliary verbs - $b a$ and $-y a$ occur in their perfect forms, i.e. $-b e$ and $-y e$, respectively. The future compound verb forms can use either the forms - $b a$ and $-y a$ or their perfect counterparts.
} 
from the first verb form is either omitted for some noun classes/persons (recent past imperfective, first person singular: ndibe ndibaleka 'I was running' > bendibaleka) or it merges with the auxiliary verb and the second subject concord (recent past imperfective, second person singular: ube ubaleka 'you were running' > ububaleka).

All the past and future compound verbs with the auxiliary verbs - $b a$ 'be' and -ya 'go' can be marked for the perfect aspect by adding the suffixes -ile or $-e$ to the second verb form.

Table 1: Five tenses of Xhosa, their imperfective forms, and their perfect forms. The verb ukubaleka ('to run') is shown with the first person singular subject concord throughout. In the imperfective column, the auxiliary verbs $-b a$ 'be' and $-y a$ 'go' as well as the subject concords with which they merge are in bold. In the rightmost column, the perfect suffixes -ile and $-e$ are in bold.

\begin{tabular}{|c|c|c|c|}
\hline & perfective $^{16}$ & imperfective & perfect \\
\hline remote future & $\begin{array}{l}\text { ndiya kubaleka } \\
\text { 'I will run' }\end{array}$ & $\begin{array}{l}\text { ndiya kuba ndibaleka } \\
\text { 'I will be running' }\end{array}$ & $\begin{array}{l}\text { ndiya kuba ndibaleke, } \\
\text { ndiya kuba ndibalekile } \\
\text { 'I will have run' }\end{array}$ \\
\hline $\begin{array}{l}\text { immediate } \\
\text { future }\end{array}$ & $\begin{array}{l}\text { ndiza kubaleka } \\
\text { 'I will run' }\end{array}$ & $\begin{array}{l}\text { ndiza kuba ndibaleka } \\
\text { 'I will be running' }\end{array}$ & $\begin{array}{l}\text { ndiza kuba ndibaleke, } \\
\text { ndiza kuba ndibalekile } \\
\text { 'I will have run' }\end{array}$ \\
\hline present & $\begin{array}{l}\text { ndibaleka, ndiyabaleka } \\
\text { 'I run' or 'I am running' }\end{array}$ & & \\
\hline recent past & $\begin{array}{l}\text { ndibaleke, ndibalekile } \\
\text { 'I ran' or 'I have run' }\end{array}$ & $\begin{array}{l}\text { bendibaleka } \\
(<\text { ndibe ndibaleka }) \\
\text { 'I was running' or 'I ran' }\end{array}$ & $\begin{array}{l}\text { bendibaleke, } \\
\text { bendibalekile } \\
\text { 'I had run' }\end{array}$ \\
\hline remote past & $\begin{array}{l}\text { ndabaleka } \\
\text { 'I ran' }\end{array}$ & $\begin{array}{l}\text { ndandibaleka } \\
(<\text { ndaye ndibaleka) } \\
\text { 'I ran' or 'I was running' }\end{array}$ & $\begin{array}{l}\text { ndandibaleke, } \\
\text { ndandibalekile } \\
\text { 'I had run' }\end{array}$ \\
\hline
\end{tabular}

As pointed out in section 1, numerous points of disagreement still exist in the literature regarding the semantics of some verb forms in the Nguni languages. Some scholars claim that the Nguni recent past form has aspectual properties, and that this form denotes a completed or a perfective eventuality (de Clercq 1961; Wentzel and Botha 1972; Ziervogel, Louw and Taljaard 1976; Botne and Kershner 2000). However, other scholars such as Mncube (1957) see the form as expressing the purely temporal category of recent past. McLaren (1936), Bennie (1953), Louw and Jubase (1963), Davey (1973), Du Plessis (1978), and Rose, Beaudoin-Lietz and Nurse (2002) interpret the recent past forms as marked for both tense and aspect.

The interpretation of the imperfective form is another significant point of disagreement. Whereas McLaren (1936), Bennie (1953), Louw and Jubase (1963), Davey (1973), Groenewald (2014), Nurse (2008), Doke (1935, 1981), Taljaard, Khumalo and Bosch (1991), van Eeden (1956), van Rooyen (1977), Cope (1984), Canonici (1987), and Taljaard and Bosch (1988)

\footnotetext{
${ }^{16}$ The present tense form cannot be considered a form that exclusively expresses the perfective aspect. Therefore, it is viewed as aspect-neutral in the present study.
} 
ascribe to this form both temporal and aspectual semantics ${ }^{17}$, Hall (2005) and Posthumus (2008) claim that it is not an aspectual marker, but a relative tense.

\subsection{The perfective and imperfective aspect in Xhosa}

The first question that needs to be addressed at this point is why the present study assumes that Xhosa has the perfective/imperfective aspectual opposition. This question is related to the semantics of compound verbs with the auxiliary verbs - $b a$ 'be' and $-y a$ 'go' ${ }^{18}$.

The auxiliary verb - $b a$ 'be' occurs both in habitual (12-13) and progressive (14) contexts.

Be-ndi-cul-a u-bu-suku b-onke.

be.PRF-1SG-sing-FV AUG-14-night 14-whole

'I sang the whole night.'

$$
\begin{array}{lll}
\text { Be-ndi-phangel-a } & y \text {-onke } & \text { i-mi-hla. } \\
\text { be. PRF-1SG-work-FV } & \text { 4-every } & \text { AUG-4-day } \\
\text { 'I worked every day.' } &
\end{array}
$$
Ba-fik-e
2-arrive-
$x a$
be-ndi-bhal-a
i-leta.
'They arrived when I was writing a letter.'

The fact that the habitual and the progressive meaning share the same marker is strong evidence that Xhosa has the imperfective aspect. Accordingly, all verb forms in which the imperfective aspect is not marked are considered perfective ${ }^{19}$.

An issue regarding the perfective/imperfective opposition in Xhosa that needs to be discussed is the view of Hall (2005) and Posthumus (2008) that compound verbs with -ba do not represent aspectual categories, but relative tenses that are simultaneous with R. For example, according to their analysis, bendibhala 'I was writing' in (14) would coincide with R, which is bafike 'they arrived'. However, the understanding of relative tenses that will be adopted in this paper, formulated by Nurse (2008), assumes that relative tenses must be related to a previously established point in time. In Xhosa, compound verbs with $-b a$ and $-y a$ can be used without previously introducing a point in time with which these verbs coincide. Consider the dialogue in $(15)^{20}$, in which the past eventuality of walking (bendihamba I walked') is not linked to any specific point in the past.

\footnotetext{
${ }^{17}$ With the exception of van Rooyen (1977), Hall (2005), and Posthumus (2008), all the scholars mentioned here refer to these forms as "continuous", "durative" or "imperfect" tenses (Posthumus 2008), which shows that they do not make a clear distinction between tense and aspect. However, the fact that all of them (with the exception of Hall (2005) and Posthumus (2008)) label these forms as "continuous" or "durative" implies that they recognise these verb forms' aspectual semantics. Van Rooyen (1977) describes these verb forms as the "imperfective aspect" (Posthumus 2008).

${ }^{18}$ The present study focuses on the perfective/imperfective opposition in the recent past tense only. Therefore, the aspectual semantics of the compound verb forms with the auxiliary verb -ya 'go' will not be discussed further.

${ }^{19}$ This view is in accordance with Nurse's (2008) observation that the perfective aspect in Bantu languages is usually unmarked.

${ }^{20}$ Example taken from the corpus.
} 

'So, how did you come here from Grahamstown?' (literally: Now how are you coming here from Grahamstown?)
A: Be-ndi-hamb-a
ngee-nyawo ezi za-m $m^{21}$.
be.PRF-1SG-go-FV
INSTR 110 -foot 10.DEM POSS.10-1SG
'On foot.' (literally: I walked with my own feet/these feet of mine).

The main verb uza 'you are coming' in the question Ngoku uza ngantoni ukuvela eRhini? is in the present tense. Hence, no reference is made to a past time with which a relative past tense could be simultaneous.

\section{The present study}

As indicated in section 1, the present study investigates whether perfective verbs in Xhosa are quantised and bounded, as well as whether imperfective verbs are homogenous and unbounded. ${ }^{22}$ The data were taken from the three Resource Management Agency (RMA) corpora of Xhosa mentioned in the introduction. The texts used for the present study are of various genres, with novels and magazine articles constituting the largest part of the corpora. ${ }^{23}$

\subsection{Data}

The study analyses the recent past perfective and imperfective verb forms of the following frequent verbs: -hamba 'go', 'leave', 'walk'; -bhala 'write'; -sebenza 'work'; -fumana 'find'; -bamba 'catch', 'hold'; -thatha 'take'; -fika 'arrive'; -wa 'fall'; -funa 'want'; -gqiba 'finish'; and -phila 'be/get well' 'live', 'be healthy'. These verbs were chosen based on their lexical aspect. Whereas -bhala, -sebenza, and -funa are non-inchoative, -hamba, -bamba, -fumana, -thatha, -fika, -wa, -gqiba, and -phila ${ }^{24}$ are inchoative. The verb forms used in the test are henceforth referred to as the "selected verb forms". A total of 96 excerpts were chosen, but some excerpts contain more than one selected verb form. Therefore, the total number of selected verb forms is 101. Fifty selected verb forms are in the imperfective and 51 are in the perfective. For ease of reference, each selected verb form has been allocated a number (e.g. -hamba 2, -fika 7).

\footnotetext{
${ }^{21}$ Example taken from the corpus.

${ }^{22}$ In this test, the terms "bounded", "unbounded", "quantised", and "homogenous" refer to the boundary at the level of the clause at which a verb phrase appears (with its temporal and aspectual markers), as opposed to the boundedness encoded in the lexical aspect of the verb phrase.

${ }^{23}$ Whereas the novels were originally written in Xhosa, the articles in the corpora had been translated from other languages.

${ }^{24}$ A suitable test for distinguishing inchoative from non-inchoative verbs is to create a sentence in which the first clause contains the recent past perfective form, e.g. ndisebenzile 'I worked'. The second clause of the sentence then reads kodwa andigqibanga 'but I did not finish' or kodwa andiphumelelanga 'but I did not succeed', in order to cancel the interpretation of completion in the first clause. This test was devised by Dowty (1979), who uses it to detect accomplishments. This is the only situation type that yields grammatical sentences when tested, because completion entails a durative nucleus. In the present study, non-inchoative verbs will yield felicitous sentences when tested, since they have a durative nucleus; whereas sentences with inchoative verbs will be infelicitous.
} 


\subsection{Test: Homogenous and quantised eventualities}

As pointed out in section 4, this test investigates whether perfective verb phrases are quantised and whether the imperfective ones are homogenous. The homogenous/quantised distinction should directly affect the ability of a verb phrase to hold true at more than one point in time, because bounded, quantised ones do not hold true until the boundary has been reached. Furthermore, quantised verb phrases cease to hold true immediately after the boundary. Therefore, the hypothesis of this test is as follows:

The verb phrases of imperfective verbs hold true at more than one point in time, whereas the verb phrases of perfective verbs hold true at one point only.

\subsubsection{Methodology}

The truth-conditionality of each clause will be tested by asking the question 'Could the clause possibly hold true $\mathrm{X}$ amount of time before the endpoint of the eventuality it denotes?' In (15), the sentence Bendihamba ngeenyawo ezi zam 'I walked with my own feet/these feet of mine' refers to the eventuality of walking home all the way from Grahamstown, which lasted for several days. The point in time that precedes the endpoint of the eventuality and at which the truth-conditionality of the clause is tested can be placed 10 hours before the speaker's arrival at home. In this case, the speaker could say that the sentence Bendihamba ngeenyawo ezi zam holds true 10 hours prior to his arrival (the endpoint of the eventuality). Hence, the verb phrase in the sentence Bendihamba ngeenyawo ezi zam is homogenous, and the sentence holds true at more than one point in time.

However, in a sentence like $(16)^{25}$, the verb phrase cannot hold true several days before 18 July.

$$
\begin{aligned}
& \text { U-gqib-e i-mi-nyaka e-ng-a-ma-78 ngo-m-hla we-18 ku-Julayi } \\
& \text { 1-finish-PRF AUG-4-year REL.4-COP-ADJ.6-78 INSTR\3-3-day POSS.3\9-18 17-July } \\
& \text { 'He turned } 78 \text { on } 18 \text { July.' }
\end{aligned}
$$

That means that the verb phrase in (16) is quantised. The selected moment used to test the semantics of the verb phrase is placed a certain amount of time prior to the endpoint of the eventuality, and will henceforth be referred to as the "checkpoint". The amount of time that elapses between the checkpoint and the endpoint varies depending on the duration of the reallife eventuality. In the eventuality of a vase falling, the 'suitable' checkpoint would precede the endpoint by five seconds; whereas in the case of a couple getting married, a more suitable checkpoint would be located a day before the wedding ceremony.

\subsubsection{Results}

As predicted by the hypothesis, 47 out of 50 imperfective verb phrases could hold true at the checkpoint. With respect to the perfective verb phrases, 36 out of 51 denoted eventualities that could hold true only at the endpoint and at no other point in time. A lower number of perfective than imperfective verbs confirmed the hypothesis.

\footnotetext{
${ }^{25}$ Example taken from the corpus.
} 


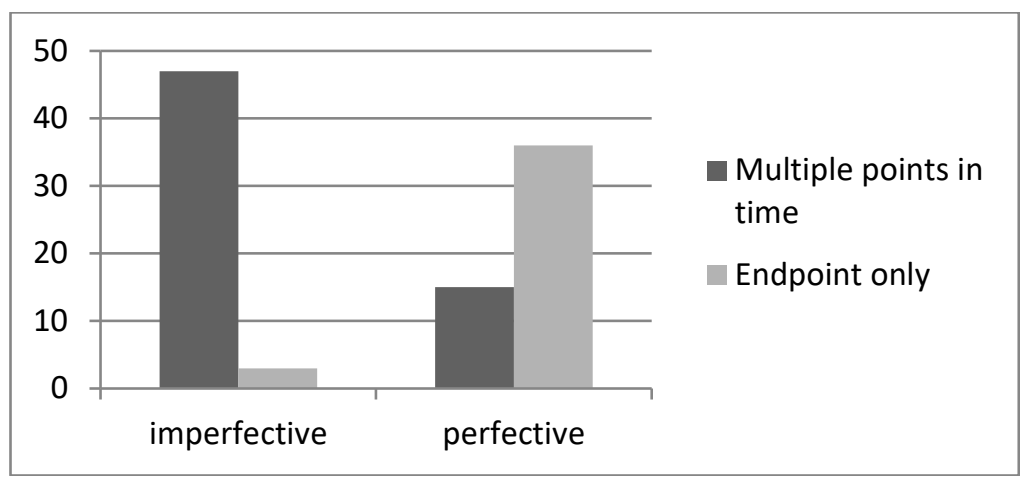

Figure 4: Clauses that hold true at more than one point in time (dark grey) and clauses that hold true at the endpoint of the eventuality only (light grey)

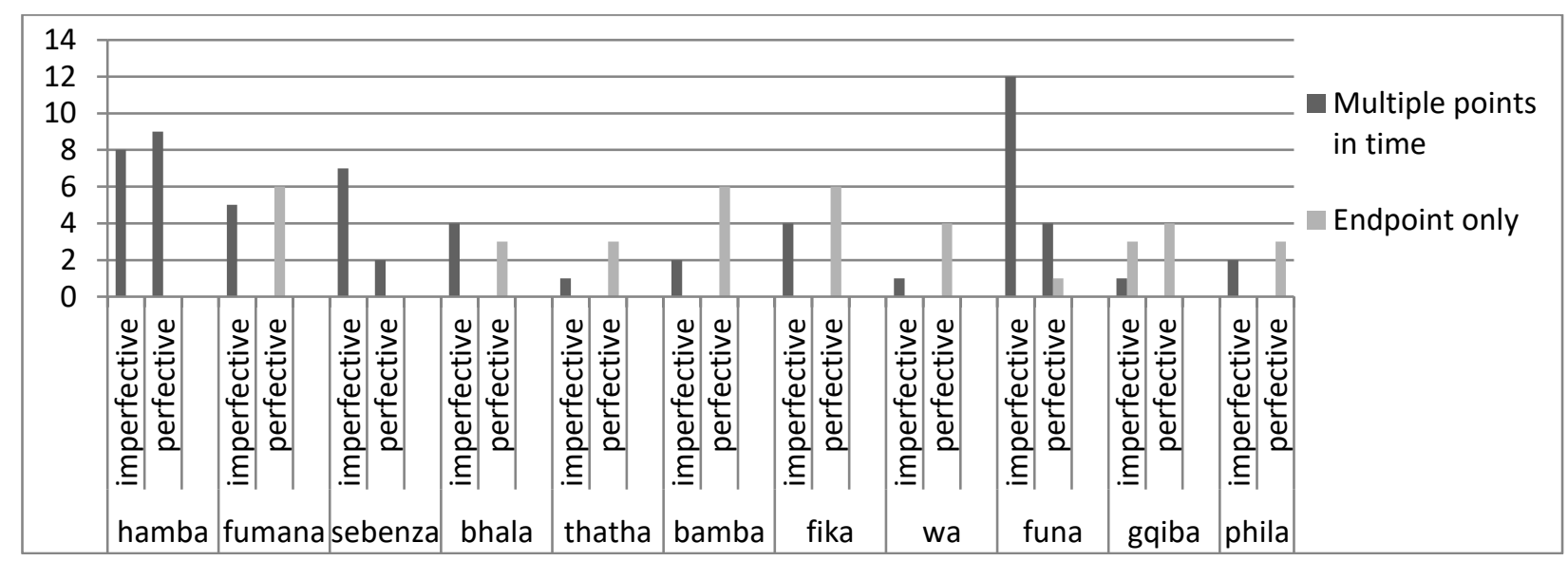

Figure 5: Perfective and imperfective verb phrases according to the main verb

When looking at the main verbs, Figure 10 shows that -fumana 'get'; -thatha 'take'; -bamba 'catch'; -fika 'arrive'; -wa 'fall'; and -phila 'live', 'get well', 'be healthy' align with the predictions within both imperfective and perfective verb phrases.

The clauses that contradict the prediction include the verbs -hamba 'go', 'leave', 'walk'; -sebenza 'work'; -bhala 'write'; -funa 'want'; and -gqiba 'finish'. The three imperfective verb phrases that contradict the hypothesis (in that they hold true only at the endpoint) involve the verb -gqiba. The 15 perfective verb phrases that contradict the hypothesis (in that they hold true at the checkpoint) include 9 instances of -hamba, 2 instances of -sebenza, and 4 instances of -funa.

\subsubsection{Analysis}

The hypothesis has been confirmed by almost all of the selected imperfective verb phrases, thus showing that these as a rule refer to homogenous eventualities. However, as many as one-third of the perfective verb phrases contradict the hypothesis, in that they represent homogenous eventualities. The examples that contradict the hypothesis may provide new insights into the properties of grammatical aspect in Xhosa. 
As mentioned in the previous section, the verb phrases that confirm the hypothesis contain the following verbs: -fumana 'get'; -thatha 'take';-bamba 'catch', 'hold'; -fika 'arrive'; -wa 'fall'; and -phila 'live', 'get well', 'be healthy'. What they have in common is that they are inchoative verbs. The only two inchoative verbs that do not confirm the hypothesis are -hamba 'go', 'leave', 'walk' and -gqiba 'finish'.

\section{Inchoative verbs + perfective aspect}

As predicted by the hypothesis, with the exception of -hamba 'go', 'walk', 'leave', all of the inchoative verbs in the perfective verb phrases denote quantised eventualities. All instances of the verb-hamba that combine with the perfective aspect are homogenous:

(17) - hamba 9:

U-hamb-e njani kodwa?

2SG-go-PRF how but

'How did your journey go?' (literally: How did you go?)

(18) - hamba 10:

Hayi, ndi-hamb-il-e nje.

no 1SG-go-DISJ-PRF just (literally: I just went)

(A response to the question in -hamba 9, in which the speaker wishes to express that his journey was uneventful, as there were no obstacles or any good news that he could report);

(19) - hamba 11:

Emva kwee-ntsuku ezin-tathu ndi-hamb-e no-Crossby

after 17\10-day\10 ADJ.10-three 1SG-go-PRF COM $\backslash 1$ a-Crossby

sa-y-a ku-prekthiz-a kwi-bala la-se-Temong :Section

1PL.CNS.PST ${ }^{26}$-go-FV 15-practice-FV 17\5-field POSS.5-LOC-Temong.Section

ku-futshane ne-Royal:Beechnut:Stadium

15-close COM\9-Royal.Beechnut.Stadium

'Three days later I went with Crossby to practice at the field in Temong Section close to Royal Beechnut Stadium.'

(20) - hamba 12:

A-ma-rhamente a-ng-a-ma-20000

AUG-6-member.of.congregation REL.6-COP-AUG-ADJ.6-20 000

be-ku-thi-w-a a-fikelel-e e-nkcochoyi-ni ya-se-Nhlangakazi

be.PRF-15-say-PASS-FV 6-reach-PRF LOC-10.top-LOC POSS.9-LOC-Nhlangakazi

ngo-m-hla we-si-2 ku-Januwari wa-lo nyaka-kodwa aba-nye

INSTR 13-3-day POSS.3\7-7-2 17-January POSS.3-DEM.3 3.year but ADJ.2-other

\footnotetext{
${ }^{26}$ Consecutive past, which is termed "past subjunctive" in Davey (1973) and Bryant (2007).
} 
ba-hamb-e nje xa u-hambo be-lu-sa-qal-a ba-z-a

2-go-PRF just when AUG-12.journey be.PRF-12-still-start-FV 2.CNS.PST-come-FV

ba-jik-a e-ndlel-eni ba-phind-a emva kwii-bhasi

2.CNS.PST-turn-FV LOC-9.road-LOC 2.CNS.PST-repeat-FV after 17\10-bus

e-be-zi-fik-a zi-ba-thath-e zi-ba-godus-e.

REL.CL-be.PRF-10-arrive-FV 10-OM.2-take-SBJ 10-OM.2-take.home-SBJ

'More than 20,000 devotees were said to have arrived at the top of Nhlangakazi on 2 January this year, and other devotees went one part of the way and then they turned back to take the busses that had come to take them back.'

(21) - hamba 13:

Kwi-veki e-landel-a-yo u-hamb-il-e

17\9-week REL.9-follow-FV-REL 1-go-DISJ-PERF

u-Mqede u-ku-y-a ku-gocagoc-a a-ma-phepha o-viwo

AUG-1a.Mqede AUG-15-go-FV 15-investigate- FV AUG-6-paper POSS.6\12-exam

lwe-Banga le-si-Thandathu e-Dikeni...

POSS.12\5-grade POSS.5\7-7-six LOC-Alice

'The following week Mqede went to test the exam papers of Standard 6 in Alice...'

(22) - hamba 14:

U-hamb-e na-lo wa-y-a ku-jikel-a emva

1-go-PRF COM-DEM.5 1.CNS.PST-go-FV 15-go.round- FV after

kwe-tyholo eli-shinyen-e-yo.

17\5-bush REL.5-be.dense-PRF-REL

'He went with it behind the dense bush.'

(23) - hamba 15:

Eli-ny' i-qhinga ku-ku-bek-a ii-bhotile

ADJ.5-another AUG-5.strategy COP-15-put-FV AUG-10.bottle

ezi-nge-na-nto e-ndlel-eni e-ngen-a e-ndl-wini

REL.10-NEG-COM-9.thing LOC-9.road-LOC REL.9-enter-FV LOC-9.house-LOC

u-z-e u-bek-e i-bhotile e-luhlaza e-xel-a

2SG-come-SBJ 2SG-put-SBJ AUG-9.bottle REL.9-green REL.9-indicate-FV

ukuba a-ba-nini:mzi ba-hamb-e nge-ntsimbi ye-si-8 kusasa

that AUG-2-house.owner 2-go-PRF INSTR\9-bell POSS.917-7-8 in.the.morning 
be-si-y-a e-m-sebenzi-ni.

2.PCP-INFX ${ }^{27}$-go-FV LOC-3-work-LOC

'Another trick is to put empty bottles at the entrance to the house, and put a green bottle that says that the owners of the house left at 8 in the morning when they went to work.'

(24) - hamba 16:

U-hamb-e ngee-nyawo e-hloniph-il-e

1-go-PRF INSTR 110 -foot 1.PCP-respect-DISJ-PRF

$\begin{array}{ll}\text { no-ku-hloniph-a } & \text { u-Mncekeleli } \\ \text { COM } \backslash 15-15-\text { respect-FV } & \text { AUG-1a.Mncekeleli }\end{array}$

'Mncekeleli walked out of respect.'

(25) - hamba 17:

U-hamb-e wa-y-a ku-sithel-a u-Khomoni

1-go-PRF 1.CNS.PST-go-FV 15-disappear-FV AUG-1a.Khomoni

li-m-tshel-e ukuba u-z-a ku-th-i li-phi na i-hashe

5-PCP-OM.1-adhere-PRF that 1-come-FV 15-say-FV 5-where Q AUG-5.horse

la-kowabo ku-yise, wa-ye-l-az-i nje

POSS.5-at.his.home 17-his.father 1.REM-ya.PRF-OM.5-know-FV just

yena Khomoni apho li-kho-yo

PRO.1 1a.Khomoni there 5-exist-REL

'Khomoni walked away not knowing what he would tell his father about where their horse was, and he knew where it was.'

Like all inchoative verbs, the verb -hamba has a punctual nucleus. The nucleus consists of the beginning moment of walking or traveling, followed by the coda phase, which represents the process of walking or traveling. Unlike the other inchoative verbs in the perfective, in -hamba both the nucleus and the durative coda obtain a complexive interpretation.

A large number of the examples of -hamba above (the exceptions being -hamba 9, -hamba 10, -hamba 12, and -hamba 16) possibly occur with the perfective aspect because these verb phrases represent eventualities that begin after the preceding eventualities have ceased. The phenomenon of perfective verbs indicating sequenced eventualities has been described by a number of scholars, including Galton (1976), Hopper (1979), and Borik (2002), who refer to it as "reference time movement" (henceforth "R-movement"). In eventuality sequencing, imperfective verbs represent eventualities that do not move the time forward.

The use of the perfective aspect in -hamba 9 and -hamba 10 can be explained with reference to the phenomena of information structure and focus. When the focus is on the result of an eventuality (the resulting object, the destination of a movement, or the endpoint), the verb will

\footnotetext{
${ }^{27}$ Infix inserted in the participial form in front of the monosyllabic root.
} 
be perfective. When the eventuality itself is focused (i.e. the instruments or the accomplices involved, the route of a movement, the location of the eventuality, etc.), the imperfective aspect is used (Dahl 1985). By way of example, the perfective verb upheke 'you cooked' will be used in the question Upheke ntoni? 'What did you cook?', as opposed to its imperfective counterpart ubupheka in the question Ubupheka idinala nabani? 'Who did you cook the dinner with?'. Similarly, in the question in -hamba 9, Uhambe njani kodwa? 'How did your journey go?' (literally: 'How did you go?), the speaker requests a different piece of information about the eventuality than would be the case if the verb were imperfective: Ubuhamba njani kodwa? 'How did you go/walk/travel?' The perfective form uhambe 'you went' signals that the speaker wants information about any eventualities that happened during the journey. In the question Ubuhamba njani kodwa?, the speaker uses the imperfective form ubuhamba to request information about the process of travelling, such as the route and other details about the journey itself.

The reasons for the use of the perfective aspect in -hamba 12 and -hamba 16 'violate' the rule of R-movement. Even though the verb phrases are perfective, they do not advance the time. The explanation for the aspectual choice in these two cases might be linked to focus, in that the perfective aspect 'announces' that the following clause will introduce information about new situations and eventualities.

\section{Inchoative verbs + imperfective aspect}

The inchoative verbs in the imperfective yield habitual and progressive or durative ${ }^{28}$ interpretations. Only one instance denotes a non-factual (possibly iterated) eventuality. In the durative readings of -hamba (eight instances), -phila (two instances), and -bamba (one instance), the eventuality refers to the coda phase. In the case of -hamba, that is the process of walking or traveling; whereas in the case of -phila it is the process of living. The durative example with -bamba 2 refers to the process of holding, which is used metaphorically to refer to the situation of holding meetings.

One instance of -gqiba receives a progressive interpretation. In -gqiba 2 , the process of turning 39 does not represent an inchoative eventuality which divides the timeline into a period before the birthday and after the birthday:

\footnotetext{
${ }^{28}$ In this section, "durative interpretation" refers to the shift of focus to a durative phase (onset, nucleus, or coda). This should be distinguished from progressive interpretations, in which the eventuality's nucleus is durative and is observed from one point in time.
} 
(26) - gqiba 2:

$\begin{array}{lll}\text { l-zibulo } & \text { la-khe, } & \text { u-Makhosazana, } \\ \text { AUG-5.first.born } & \text { POSS.5-1 } & \text { AUG-1a.Makhosazana }\end{array}$

u-be-gqib-a i-mi-nyaka e-ng-a-ma-39 u-bu-dala

1-be.PRF-finish-FV AUG-4-year REL.4-COP- AUG-6-39 AUG-14-age

ku-Lwesithathu e-be-si-dlan:indlebe nga-lo na-ye

17-12.Wednesday REL.CL-be.PRF-1PL-interview INSTR-DEM.12 COM-1

'His first-born, Makhosazana, was turning 39 on Wednesday when we interviewed him.'

Instead, the eventuality becomes a non-inchoative activity that holds true on the day of Makhosazana's birthday. This means that the nucleus of -gqiba is magnified to the extent that it does not represent a recognisable change of state. The durative nucleus extends before, during, and after the point(s) of the interview from which the eventuality is observed.

A large number of inchoative verbs have a habitual reading. In -fumana 1 , the verb denotes an iterated eventuality:

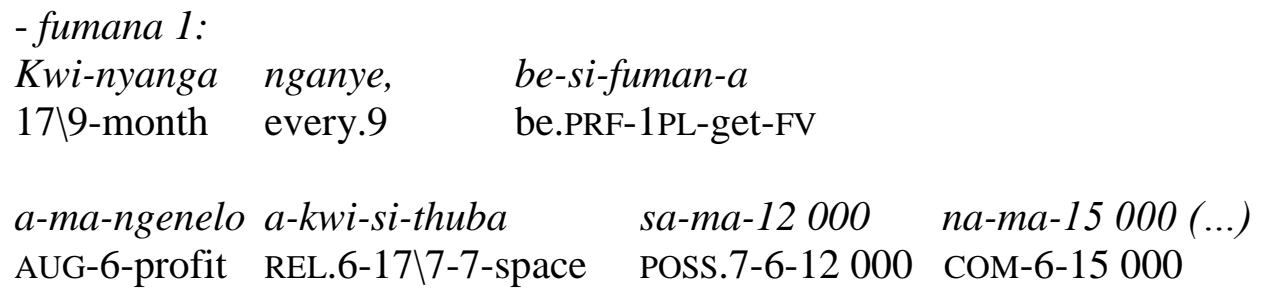

'Each month we got a profit between 12,000 and 15,000..'

In -fumana 4, it is debatable whether the same verb denotes a durative or an iterated eventuality, since the intended semantics shifts from 'get' or 'receive' to 'earn (a salary)':

(28) - fumana 4:

$\begin{array}{lll}\text { U-bu-ngakanani } & \text { bo-m-hlala:phantsi } & \text { wa-kho } \\ \text { AUG-14-extent } & \text { POSS.14\3-3-pension } & \text { POSS.3-2SG }\end{array}$

bu-xhomekek-e ekubeni u-bu-fuman-a u-m-vuzo

14-depend-PRF that 2 sG-be.PRF 2 SG-get-FV AUG-3-salary

o-ngakanani na-se-bu-nzul-wini bo-ku-khubazek-a oko

REL.3-how.much COM-LOC-14-depth-LOC POSS.14\15-15-be.disabled-FV DEM.15

'The level of your pension depends on the income you earned and the degree of your disability.'

As mentioned, three instances of -gqiba denote eventualities that contradict the hypothesis by being quantised. In these cases, -gqiba holds true at only one point in time, but the imperfective 
aspect 'stretches' the punctual nucleus in order to make its relation to the surrounding eventualities (and thus also the eventuality's temporal location) less specific. For example, in -gqiba 3 it is not specified at which point the subject finished reading relative to the process of meeting the journalists:

(29) - gqiba 3:

U-be-bonakal-a ukuba u-ne-si-thukuthezi-

1-be. PRF-be.visible-FV that 1-COM\7-7-loneliness

u-be-gqib-a ku-fund-a i-magazini e-b-i-phezu- kodwa

1-be.PRF-finish-FV 15-read-FV AUG-9.magazine REL.9-be.PRF-9-on.top but

e-khangelek-a e-phil-il-e ku-ne-nto

1.PCP-look.like-FV 1.PCP-be.well-DISJ-PRF 17-COM\9-thing

e-be-si-yi-lindel-e e-ndod-eni e-soloko

REL.CL-be. PRF-1PL-OM.9-expect-PRF LOC-9.man-LOC REL.9-always.do

i-se-si-rhox-weni

9- LOC-7-isolated.place-LOC

'He looked as if he was lonely - he (just) finished reading the magazine which was on top of the table - but he looked much better than what we were expecting from a man who is always in an isolated place.'

The process of reading may have finished before the journalists saw him, or it may have ceased at any point between the moment they saw him and the moment they introduced themselves. Another example of temporal vagueness is seen in -gqiba 4:

(30) - gqiba 4:

$\begin{array}{llll}\text { U-ng-om-nye } & \text { wa-bona } & \text { ba-ntu } & \text { aba-dala } \\ \text { 1-COP-ADJ.1-one } & \text { POSS.1-PRO.2 } & \text { 2-person } & \text { ADJ.2-old }\end{array}$

e-hlabathi-ni, $\quad$ u-be-gqib-a i-mi-nyaka e-li-106

LOC-5.world-LOC 1-be.PRF-finish-FV AUG-4-year REL.4-COP.5-106

ngo-Julayi

INSTR \1a-July

'She is one of the oldest people on earth, she turned 106 in July.'

In (29), the speaker chooses not to refer to the eventuality as a definite point in time that is included in the time adverbial ngoJulayi 'in July'. Instead, it is represented as an eventuality that could hold true at any point within the month of July. Perhaps the goal of this use of the imperfective aspect is to emphasise that the event did not occur long ago, since the month of July is not far from the month of September, where $\mathrm{S}$ is located. 
As in the previous example, in -gqiba 1 the imperfective verb emphasises the short temporal distance between the eventuality and $\mathrm{S}$, thus creating an interpretation similar to that of the English adverb "just":

- gqiba 1:
U-bu-gqib-a
ku-ndi-xelel-a
ukuba u-hamb-a
2SG-be.PRF 2 SG-finish-FV
15-OM.1sG-tell-FV
that
2SG-go-FV

$\begin{array}{lllll}u \text {-fun- } a & u \text {-lw-azi } & \text { lwe-thisisi } & y a-k h o & y e-M a s t e r s . \\ \text { 2SG-want-FV } & \text { AUG-12-knowledge } & \text { POSS.1219-thesis } & \text { POSS.9-2SG } & \text { POSS.919-Masters }\end{array}$

'You have just told me that you travel because you want information for your Master's thesis' (literally: You were finishing telling me that you travel...).

The only non-factual inchoative eventuality that is denoted by the imperfective verb ebekufumana 'he/she/it has got' is in -fumana 3.

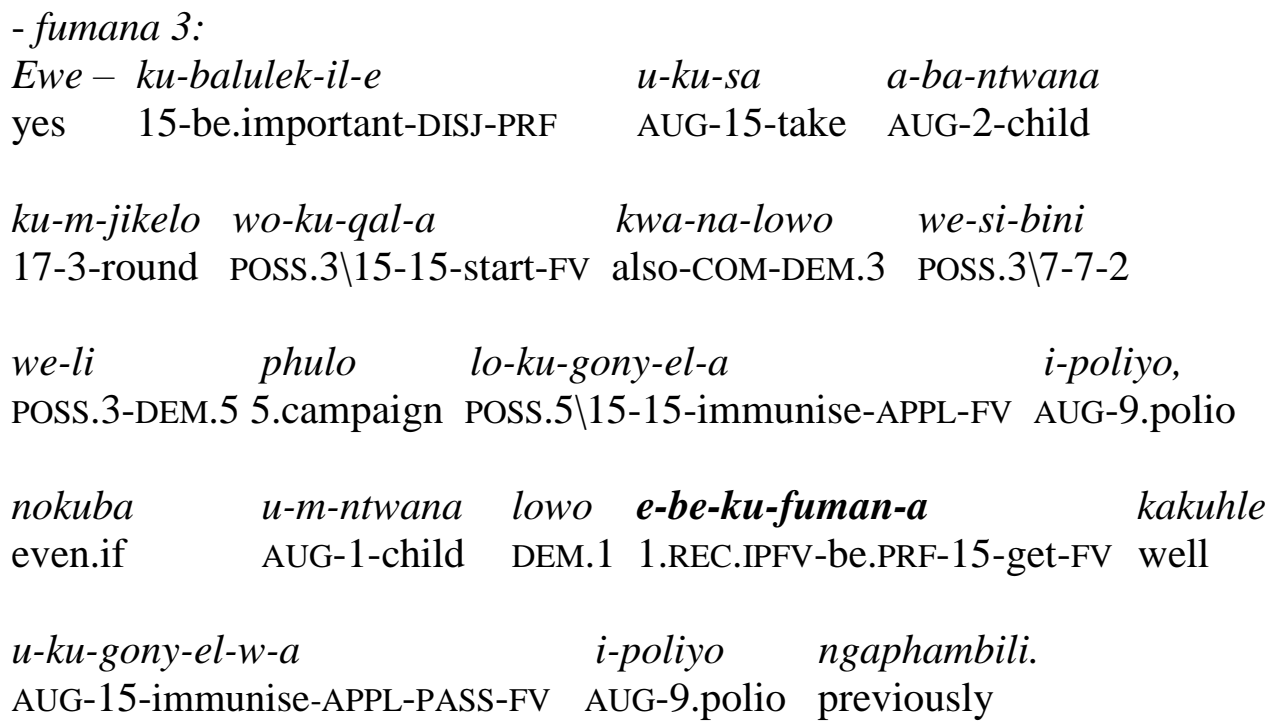

'Yes, it is important to take your children to the first round as well as to the second round of vaccination campaign against polio, even if the child has received the vaccination properly before.'

The speaker does not know whether or how many times the vaccinations have occurred. Therefore, s/he does not assign the hypothetical eventuality to a specific point in time. If the eventuality of getting the vaccination was only non-factual, but the speaker knew on which occasion it could have taken place, the speaker would not refer to it with ebekufumana. However, ebekufumana in -fumana 3 refers to an infinite number of possible moments at which any child may have received the vaccination. The use of the imperfective aspect is possibly due to the fact that the hypothetical eventuality cannot be represented by a single, concrete nucleus which marks a change of state. 
Based on the evidence presented, it can be concluded that imperfective inchoative verbs either denote homogenous eventualities (in a habitual, progressive, or durative context) or quantised eventualities with an unspecified temporal location.

\section{Non-inchoative verbs + imperfective aspect}

As predicted, the imperfective clauses with non-inchoative verbs refer to the durative nuclei of -bhala 'write', -sebenza 'work', and -funa 'want'. As a result, all non-inchoative imperfective verbs in the sample represent homogenous eventualities.

\section{Non-inchoative verb + perfective aspect}

Only four non-inchoative perfective verbs denote quantised eventualities. It is arguable whether the following three non-inchoative verbs refer to quantised eventualities (complexive context), because of the direct objects that would not have existed had the process of writing not reached its endpoint ${ }^{29}$ :

(33) - bhala 5:

Ndi-bhal-e le ncwadi kuba ndi-xhalaty-is-w-a

1SG-write-PRF DEM.9 9.book because 1SG-stress\PASS-CAUS-PASS-FV

li-nani el-onyuk-e kakhulu lo-lu-tsha olu-bhubh-a-yo

COP.5-number REL.5-increase-PRF very POSS.5\12-12-youth REL.12-die-FV-REL

$\begin{array}{ll}e \text {-lali-ni } & y a-m . \\ \text { LOC-9.village-LOC } & \text { POSS.9-1SG }\end{array}$

'I wrote this book because I was worried about the highly increased number of young people that are dying in my village.'

(34) - bhala 6:

U-Abrahams u-bhal-e i-mi-bongo, ii-ncwadi

AUG-1a.Abrahams 1-write-PERF AUG-4-poem AUG-10.book

ne-ncwadi e-ngo-bomi.

COM\9-book REL.9-INSTR\14-life

'Abrahams has written poems, books, and a biography.'

(35) - bhala 7:

U-bhal-e i-ncwadi e-chaz-a i-ndlela

1-write-PRF AUG-9.book REL.9-explain-FV AUG-9.way

a-y-e w-onwab-a nga-yo.

1.SBJ-go-SBJ 1-be.happy-FV INSTR-9

\footnotetext{
29 If all the objects in -bhala 6 were plural, it would be treated as a durative eventuality. However, the autobiography (nencwadi engobomi) is a singular noun and the moment of its publication serves as the only point at which the verb phrase holds true.
} 
'She wrote a book about how happy she is.'

These three examples may be considered homogenous as well, because recent past perfective verbs do not entail that the eventualities are completed. For example, the interpretation of Ndifunde le ncwadi 'I have read this book' does not necessarily have to mean that the eventuality of reading is completed. Adding a clause which cancels the first clause's interpretation of completion does not render the sentence ungrammatical: Ndifunde le ncwadi, kodwa andigqibanga 'I have read (engaged myself in reading) this book, but I did not finish it'. The reason for the use of the perfective aspect in the three examples above is probably linked to information structure. All three examples prepare the listener for information related either to the objects of writing or to other situations unrelated to the eventuality of writing.

The fourth example of a quantised eventuality among the non-inchoative perfective verbs is a case of a complexive interpretation. In -funa 16, the verb ufune (ukwazi) 'she asked' (literally: she wanted to know) does not refer to the subject's desire to know a particular piece of information:

$$
\begin{aligned}
& \text { - funa 16: } \\
& \text { U-fun-e } \\
& \text { 1-want-PRF AUG-15-know-FV } \\
& \text { u-Nambitha } \\
& \text { AUG-1a.Nambitha } \\
& \text { ukuba ingaba } \\
& \text { that perhaps } \\
& \text { i-meko a-yi-ka-tshintsh-i na e-m-sebenzi-ni } \\
& \text { AUG-9.situation NEG-9-yet-change-NEG Q LOC-3-work-LOC } \\
& \text { ka-Khuselwa } \\
& \text { POSS.9\1a-Khuselwa }
\end{aligned}
$$

\begin{tabular}{|c|c|c|c|c|}
\hline Ndi-sebenz-e & kwi-fama & $u k u$ & \multicolumn{2}{|c|}{$i-m i-n y a k a$} \\
\hline 1-work-PRF & 17\9-farm & 9\9-chicken & \multicolumn{2}{|c|}{ AUG-4-year } \\
\hline emi-ninzi & $n d a-z u z-a$ & $w-a z i$ & \multicolumn{2}{|c|}{ olw-anel-e-yo } \\
\hline ADJ.4-many & \multicolumn{4}{|c|}{ 1.CNS.PST-get-FV AUG-12-knowledge REL.12-suffice-PRF-REL } \\
\hline \multirow{2}{*}{$\begin{array}{l}\text { kangangokuba } \\
\text { to.such.an.exten }\end{array}$} & ndi-nga-d-e & ndi-zi-qalel-e & & $e-y a-m$ \\
\hline & ent 1-can-do.until-SBJ & J 1-REFL-begin-SF & & REL.9-POSS.9-1SG \\
\hline$i$-fama & e-ncinane & kuku. & & \\
\hline
\end{tabular}

Instead, it denotes the eventuality of the subject actively asking her interlocutor a question. -funa 16 is a case of R-movement, in which the eventuality of asking follows the previous eventualities in time.

Contrary to the hypothesis, a large number of non-inchoative perfective verbs represent homogenous eventualities with a complexive interpretation: 
'I worked at a chicken farm for many years, and I got enough knowledge so that I can start my own small chicken farm.'

(38) - sebenza 9:

Ndi-sebenz-e no-Mambush i-mi-nyaka e-si-8 ngoku

1-work-PRF COM\1-Mambush AUG-4-year REL.4-COP.7-8 now

'I have worked with Mambush for eight years now.'

(39) - funa 13:

$\begin{array}{lll}\text { Si-m-fun-e } & \text { ii-yure } & \text { ezin-tathu } \\ \text { 1PL-OM.1-want-PRF } & \text { AUG-10.hour } & \text { ADJ.10-three }\end{array}$

$\begin{array}{llll}s a-z-a & s a-m-f u m a n-a & e \text {-zantsi } & e \text {-liw-eni } \\ 1 \text { PL.CNS.PST-come-FV } & \text { 1PL.CNS.PST-OM.1-find-FV } & \text { 1.PCP-below } & \text { LOC-5.cliff-LOC }\end{array}$

e-ne-nxeba e-ntloko.

1. PCP-COM\9-wound LOC-9.head

'We searched for her for three hours and we found her under the cliff with a wound on her head.'

(40) - funa 14:

U-fun-e u-ku-xing-a o-be-buz-w-a ngo-ku-th-i

1-want-PRF AUG-15-delay-FV REL.1-be.PRF-ask-PASS-FV INSTR\15-15-say-FV

u-m-az-i u-ku-thi-ni na

1-OM.1-know-FV AUG-15-say-what Q

'He wanted to postpone answering by requesting an explanation of the question.'

(41) - funa 15:

Kwa-ku-se-ku-nzima no-ku-theth-a

15.REM-15-LOC-15-difficult COM\15-15-speak-FV

e-fuman-a a-ba-jong-e nje kodwa a-ba-ntu, i-nto

1.PCP-get-FV 1.SBJ-OM.2-look.at-SBJ just but AUG-2-person AUG-9.thing

leyo e-ya-yi-b-enz-a ukuba ba-ntywizis-e,

DEM.9 REL.9-9.REM-9-OM.2-do-FV that 2-shed.tears-SBJ

aba-nye ba-fun-e u-ku-khal-a ba-phumelelis-e (...)

ADJ.2-other 2-want-PERF AUG-15-cry-FV 2-do.openly-SBJ

'He struggled to speak and he could only look at people, which made some people shed tears, while others wanted to cry openly (...)' 


\author{
- funa 17: \\ U-Elizabeth \\ AUG-1a.Elizabeth \\ u-rileks-e ii-n-wele za-khe \\ 1-relax-PRF AUG-10-hair POSS.10-1 \\ ezin-de e-sebenzis-a i-TCB:Naturals:No:Base:Creme:Relaxer, \\ ADJ.10-long 1.PCP-use-FV AUG-9.TCB.Naturals.No.Base.Creme.Relaxer
}

$\begin{array}{lllll}\text { kodwa sekunjalo } & \text { u-fun-e } & \text { a-no-ku-ku-sebenzis-a } & \text { rhoqo e-khaya } \\ \text { but nevertheless } & 1 \text {-want-PRF } & \text { REL.CL.1-COM } 15-15-15-\text { use-FV always } & \text { LOC-5.home }\end{array}$

u-ku-z-e a-phucul-e u-bu-hle be-ndalo

AUG-15-come-SBJ 1.SBJ-improve-SBJ AUG-14-beauty POSS.14\9-nature

$\begin{array}{ll}\text { bee-n-wele } & \text { za-khe (...) } \\ \text { POSS.14\10-hair } & \text { POSS.10-1 }\end{array}$

'Elizabeth has relaxed her long hair using TCB Natural No Base Creme Relaxer, but nevertheless she wanted something that she could always use at home so that she can maximise the beauty of her hair's nature (...)'

-funa 13, -funa 14, and -funa 17 represent examples of eventuality sequencing; i.e. $\mathrm{R}$-movement. The use of the perfective aspect in -sebenza 8 , -sebenza 9 , and -funa 15 seems to be related to focus, as in -bhala 5, -bhala 6 , and -bhala 7 , where it prepares the listener for information regarding other situations unrelated to the eventuality of writing.

The observations regarding the examples that cannot be explained by R-movement indicate that more research on information structure (and focus) is needed to explain the use of the perfective aspect with non-inchoative verbs.

\title{
5. Conclusion
}

The present study has shown that Xhosa is a language that distinguishes between the perfective and imperfective aspects. Even though a vast majority of verbs confirm the hypothesis that imperfective verbs tend to denote homogenous eventualities and perfective verbs tend to denote quantised eventualities, the numerous exceptions to this tendency show that the semantics of the perfective aspect in Xhosa is linked to other phenomena, too.

The semantics of the perfective/imperfective opposition is primarily linked to the notion of boundaries. As a rule, the perfective aspect is used for factual inchoative eventualities that occur once (or a specified number of times). The lower the factuality of the eventuality and the more unspecified the number of iterations of the eventuality, the higher the probability that the verb will take the imperfective aspect. Non-inchoative atelic eventualities can be either perfective or imperfective, and the choice of aspect in these cases depends not only on factuality and the number of reoccurrences, but also on information structure (focus) and R-movement.

A boundary can therefore be conceived of as a factual point in time that occurs once and indicates a change of state, i.e. a transition from one state to another. At the level of lexical aspect, boundaries are the punctual nuclei of inchoative verbs. At the level of grammatical 
aspect, the perfective aspect serves to mark a point at which a proposition (about a quantised or homogenous eventuality) is asserted.

The perfective aspect marks punctual changes of state on the timeline. All new pieces of information about other eventualities have to be aligned in relation to the existing points of time (boundaries) on the timeline. 'New' perfective verbs tend to be placed at a later point than the existing boundaries, thus creating the effect of R-movement and helping the recipient of the message to keep track of time in an eventuality sequence. Imperfective verbs do not assert propositions at one point and they do not exhibit boundaries. Therefore, when added to a narrative, imperfective verbs are often temporally unaligned relative to the existing boundaries on the timeline.

As has been demonstrated, in the area of information structure, boundaries created by the perfective aspect prepare the hearer for information about a new eventuality in the following clause, whereas the lack of a boundary (imperfective aspect) indicates that the following clause will provide more information about the situation that has already been introduced. More research at the intersection of grammatical aspect and information structure is needed to provide evidence about the role of boundaries as indicators of the content surrounding a clause.

\section{References}

Bach, E. 1986. The algebra of events. Linguistics and Philosophy 9: 5-16.

Bary, C. 2009. The perfective/imperfective distinction: Coercion or aspectual operators? In L. Hogeweg, H. de Hoop and A. Malchukov (eds.) Cross-linguistic semantics of tense, aspect and modality. Amsterdam, Philadelphia: John Benjamins. pp. 33-53.

Bennie, W. G. 1953. A grammar of Xhosa for the Xhosa-speaking. Lovedale: Lovedale Press.

Beuchat, P. D. 1966. The verb in Zulu. Johannesburg: Witwatersrand University Press.

Bohnemeyer, J. 2014. Aspect vs. relative tense: The case reopened. Natural Language \& Linguistic Theory 32(2): 955-971.

Botne, R. 1983. On the notion 'inchoative verb' in Kinyarwanda. In F. Jouannet (ed.) Le Kinyarwanda: Études linguistiques. Paris: SELAF. pp. 149-180.

Botne, R. and T.L. Kershner. 2000. Time, tense, and the perfect in Zulu. Afrika und Übersee 83: $161-181$.

Borik, O. 2002. Aspect and reference time. Unpublished PhD dissertation. Utrecht: Utrecht Institute of Linguistics OTS.

Bryant, A. 2007. Xhosa for second-language learners. Rondebosch: Alexandra Bryant.

Canonici, N. N. 1987. The grammatical structure of Zulu. Durban: University of Natal. 
Chung, S. and A. Timberlake. 1985. Tense, aspect, and mood. In T. Shopen (ed.) Grammatical categories and the lexicon. Cambridge: Cambridge University Press. pp. 202-258.

Comrie, B. 1976. Aspect. Cambridge: Cambridge University Press.

Cope, A. T. 1984. Zulu: A comprehensive course. Durban: University of Natal.

Crane, T. M. 2012. Completion and dissociation in Totela tense and aspect. Selected Proceedings of the $42^{\text {nd }}$ Annual Conference on African Linguistics. Somerville: Cascadilla Proceedings Project. pp. 208-220.

Dahl, Ö. 1985. Tense and aspect systems. Oxford: Blackwell.

Davey, A. S. 1973. Moods and tenses of the verb in Xhosa. MA thesis. Pretoria: University of South Africa.

de Clercq, J. 1961. Verlede tyd, subjunktief en konsekutief in Zoeloe. Feesbundel vir prof. Dr. Jan Antonie Engelbrecht. Johannesburg: Afrikaanse Pers Beperk.

de Swart, H. 1998. Aspect shift and coercion. Natural Language \& Linguistic Theory 16: 347385.

Dickey, S. M. 2000. Parameters of Slavic aspect: A cognitive approach. Stanford: CSLI Publications.

Doke, C. M. 1935. Bantu linguistic terminology. London, New York \& Toronto: Longmans, Green \& Co.

Doke, C. M. 1981. Textbook of Zulu grammar. $6^{\text {th }}$ edition. Cape Town: Longman Southern Africa.

Dowty, D. R. 1979. Word meaning and Montague grammar. The semantics of verbs and times in generative semantics and in Montague's PTQ. Dordrecht: Reidel.

Du Plessis, J. A. 1978. isiXhosa 4. Cape Town: Oudiovista Produksies.

Eiselen, E.R. and M.J. Puttkammer. 2014. Developing text resources for ten South African languages. Proceedings of the $9^{\text {th }}$ International Conference on Language Resources and Evaluation. Reykjavik, Iceland. pp. 3698-3703.

Freed, A. 1980. The semantics of English aspectual complementation. Dordrecht: Reidel.

Galton, H. 1976. The main functions of the Slavic verbal aspect. Skopje: Macedonian Academy of Sciences and Arts.

Gowlett, D. 2003. Zone S. In D. Nurse and G. Philippson (eds.) The Bantu languages. London: Routledge. pp. 609-638. 
Groenewald, H. C. 2014. A re-evaluation of tenses in isiZulu. Literator 35 (1). Available online: http://dx.doi.org/10.4102/lit.v35i1.1062.

Gvozdanović, J. 2011. Perfective and imperfective aspect. In R. Binnick (ed.) The handbook of tense and aspect. Oxford: Oxford University Press.

Hall, L. 2005. The be-relative tenses of Zulu. MA thesis. Pretoria: University of Pretoria.

Herodotus. 2003. Histoires, livre 1. Budé. Paris: Les belles lettres.

Hinrichs, E. 1986. Temporal anaphora in discourses of English. Linguistics and Philosophy 9: 62-82.

Hopper, P. J. 1979. Aspect and foregrounding in discourse. Syntax and semantics 12 Discourse and Syntax. pp. 213-241.

Jakobson, R. 1957. Shifters, verbal categories, and the Russian verb. Selected writings II. The Hague: Mouton. pp. 130-147.

Johnson, M. R. 1981. A unified temporal theory of tense and aspect. In P. Tedeschi and A. Zaenen (eds.) Syntax and semantics 14: Tense and aspect. pp. 145-175.

Kamp, H. and U. Reyle. 1993. From discourse to logic. Dordrecht: Kluwer.

Klein, W. 1994. Time in language. London: Routledge.

Lindstedt, J. 1985. On the semantics of tense and aspect in Bulgarian. Helsinki: University of Helsinki Press.

Louw, J. A. and J.B. Jubase. 1963. Handboek van Xhosa. Johannesburg: Bonapers Beperk.

McLaren, J. 1936. A Xhosa grammar. London: Longmans.

Mourelatos, A. P. D. 1981. Events, processes, and states. In P. Tedeschi and A. Zaenen (eds.) Syntax and semantics 14: Tense and aspect. pp. 191-212.

Mncube, F. S. M. 1957. Xhosa manual. Johannesburg: Juta \& Co. Limited.

Nurse, D. 2008. Tense and aspect in Bantu. Oxford: Oxford University Press.

Nxopo, M. C. 1993. The meaning of the four basic tenses in Xhosa. MA thesis. Stellenbosch: University of Stellenbosch.

Partee, B. 1984. Nominal and temporal anaphora. Linguistics and Philosophy 7: 243-286.

Posthumus, L. 2008. Naming of the so-called continuous past tenses of the south-eastern Bantu languages with particular reference to Zulu. South African Journal of African Languages 28(1): 69-79. 
Reichenbach, H. 1947. Elements of symbolic logic. London: Macmillan.

Rose, S., C. Beaudoin-Lietz and D. Nurse. 2002. A glossary of terms for Bantu verbal categories: With special emphasis on tense and aspect. München: Lincom Europa.

Rothstein, S. 2004. Structuring events. A study in the semantics of lexical aspect. Oxford: Blackwell.

Roux, J.C., P.H. Louw and E.C. Botha. 2001. African speech technology telephone speech databases. Proceedings of the $12^{\text {th }}$ Annual Symposium of the Pattern Recognition Association of South Africa (PRASA). Pretoria: University of Pretoria. pp. 115-119.

Snyman, D., G.B. van Huyssteen and W. Daelemans. 2012. Cross-lingual genre classification for closely related languages. Proceedings of the $22^{\text {nd }}$ Annual Symposium of the Pattern Recognition Association of South Africa (PRASA). pp. 132-137.

Taljaard, P. C. and S.E. Bosch. 1988. Handbook of isiZulu. Pretoria: J.L. van Schaik.

Taljaard, P. C., J.N. Khumalo and S.E. Bosch. 1991. Handbook of siSwati. Pretoria: J.L. van Schaik.

Vendler, Z. 1967. Linguistics and philosophy. Ithaca, New York: Cornell University Press.

Van Eeden, B. I. C. 1956. Zoeloe-grammatieka. Grahamstown: Universiteitsuitgewers en Boekhandelaars (Edms) Beperk.

Van Rooyen, C. S. 1977. Die Zulupredikaat en enkele verskynsels wat daarmee saamhang. Doctoral dissertation. Pretoria: University of South Africa.

Wentzel, P. J. and J.J. Botha. 1972. Xhosa taalboek. Johannesburg: Perskor Uitgewery.

Ziervogel, D., J.A. Louw and P.C. Taljaard. 1976. A handbook of the Zulu language. Pretoria: J.L. van Schaik. 